\title{
Shared Decision-Making after Implementation of the Chronic Care Model (CCM) - An Evaluative Approach
}

\author{
Anne Lise Holm ${ }^{1}$, Anne Lyberg1, Ingela Berggren ${ }^{1,2}$, Elisabeth Severinsson ${ }^{1}$ \\ ${ }^{1}$ The Centre for Women's, Family and Child Health, Faculty of Health Sciences, Buskerud \& Vestfold University \\ College, Kongsberg, Norway \\ ${ }^{2}$ The Department of Nursing, Health and Culture, University West, Trollhättan, Sweden \\ Email: ${ }^{*}$ anne.holm@hsh.no, anne.lyberg@hbv.no, ingela.berggren@hv.se, elisabeth.severinsson@hbv.no
}

Received 25 August 2014; revised 11 October 2014; accepted 10 November 2014

Academic Editor: Fiona Nolan, University College London, UK

Copyright $@ 2014$ by authors and Scientific Research Publishing Inc.

This work is licensed under the Creative Commons Attribution International License (CC BY).

http://creativecommons.org/licenses/by/4.0/

c) (7) Open Access

\begin{abstract}
Background: In paternalistic models, healthcare providers' responsibility is to decide what is best for patients. The main concern is that such models fail to respect patient autonomy and do not promote patient responsibility. Aim: To evaluate mental healthcare team members' perceptions of their own role in encouraging elderly persons to participate in shared decision-making after implementation of the CCM. The CCM is not an explanatory theory, but an evidence-based guideline and synthesis of best available evidence. Methods: Data were collected from two teams that took part in a focus group interview, and the transcript was analysed by means of qualitative thematic analysis. Results: One overall theme emerged-Preventing the violation of human dignity based on three themes, namely, Changing understanding and attitudes, Increasing depressed elderly persons' autonomy and Clarifying the mental healthcare team coordinator's role and responsibility. The results of this study reveal that until recently, paternalism has been the dominant decision-making model within healthcare, without any apparent consideration of the patient perspective. Community mental healthcare can be improved by shared decision-making in which team members initiate a dialogue focusing on patient participation to prevent the violation of human dignity. However, in order to determine how best to empower the patient, team members need expert knowledge and intuition.
\end{abstract}

\section{Keywords}

Chronic Care Model, Decision-Making, Depressive Ill Health, Focus Group Interviews,

"Corresponding author.

How to cite this paper: Holm, A.L., Lyberg, A., Berggren, I. and Severinsson, E. (2014) Shared Decision-Making after Implementation of the Chronic Care Model (CCM)-An Evaluative Approach. Open Journal of Nursing, 4, 824-835. 


\section{Participation, Team}

\section{Introduction}

The World Health Organization [1] policy is that community mental health service users should be active and included in decisions related to them. Shared decision-making, which is closely related to concepts of patientcentred care, patient empowerment and evidence-based patient choice, is a collaborative endeavour in which patient and physician share information and intuitions [2] [3]. According to Flottorp et al. [4], a health system is a product of external pressures as well as its structure and culture. Without active user participation, such external pressure and top-down control will not lead to improvement [4]. Participation and shared decision-making mean that users gain more control of their life situation and feel less helpless [5]. The Shared decision-making has been described as a middle way between the "paternalistic" and "informed choice" models [2]. In paternalistic models, healthcare providers' responsibility is to decide what is best for patients and the main concern is that such models fail to respect patient autonomy and do not promote patient responsibility [6]. Drake and Deegan [7] argue that when the patient is compliant, shared decision-making is a virtue. But when there is disagreement about treatment, she/he is deemed to "lack insight" and participation and shared decision-making can constitute a risk of wrong decisions. Thus mental healthcare providers seem to need new insight to address the problems inherent in shared decision-making for depressed elderly persons [8]-[10]. The Code of Ethics for Nurses comprises ethical standards that guide nurses in various ethically complex situations and can lead to a conflict of values in shared decision-making [11] for example when planning treatment and care. To increase confidence in user participation and shared decision-making, power issues must be addressed within a safe learning environment [12]. In a review of patient involvement and collaboration in shared decision-making it was found that interventions to increase collaborative care had a positive effect on patient satisfaction and health outcomes [13].

\subsection{Problem Statement}

This study represents the evaluative phase of a Norwegian research project on how to manage depression in older persons [14]-[18]. More than a decade ago Wagner et al. [14] stated that the care of persons who suffer from chronic conditions such as depression cannot be provided by existing systems because these systems lack the necessary prerequisites. Depression is described as a socially and physically disabling condition associated with poor self-care, adverse medical outcomes, increased mortality and risk of suicide [19]. The Chronic Care Model (CCM) was introduced by Wagner et al. [14] [20] and later by WHO in the policy brief by Coulter et al. [21] to promote quality in the management of long-term conditions such as depression, by means of a more integrated organization of care. The CCM is not an explanatory theory, but an evidence-based guideline and synthesis of best available evidence. The model is intended to be flexible and open to change when new evidence emerges. Thus in recent years, several organizations and professionals specializing in the management of depression have adopted the CCM framework. The CCM consists of six main elements: 1) the health system; 2) clinical information systems; 3) decision support; 4) delivery system design; 5) self-management support; 6) community, which includes organizations and resources for patients [14] [20]. The CCM implies user participation in shared decision-making in addition to a team approach based on productive interactions as well as an informed and empowered patient, where the latter's role in participation is emphasized. However, there is still a lack of knowledge about the responsibility of the mental healthcare team in shared decision-making in collaboration with the depressed elderly person. In order to empower patients, the team members have to reflect and make judgments to allow the depressed elderly persons to play an active role in shared decision-making [14] [20] [22] [23]. Nevertheless, the role of mental healthcare professionals in shared decision-making is often unclear [24]. Two studies identified the value of information and communication in shared decision-making and suggested that if the patient lacks knowledge of depression, its severity will increase [25] [26]. Shared decision-making has been found to reduce lack of control, loneliness and isolation as well as lead to improved self-esteem [27]. However, if elderly persons are to feel comfortable about participating in their own care they must have adequate support [28].

\subsection{Aim and Research Question}

The aim of this study was to evaluate mental healthcare team members' perceptions of their own role in en- 
couraging elderly persons to participate in shared decision-making after implementation of the CCM. The research question was "what are the team members' perceptions of their own role in encouraging elderly persons to participate in shared decision-making".

\section{Methodology}

\subsection{Design}

The project had a qualitative inquiry design [29], which Rolfe [30] described as an important process for generating new evidence for practice.

\subsection{Participants and Data Collection}

This follow-up study utilised a focus group for data collection. The participants were one mental healthcare team comprising three mental health nurses (Team A) and one experienced geriatric nurse on a psychogeriatric team (Team B) based in a specialist geriatric hospital on the west coast of Norway. The participants were interviewed 1 year after the first two focus group sessions reported in two previous studies [16] [17]. All the participants had over 20 years' experience of working with different kinds of mental illnesses, such as depression. They were all women, with a mean age of 55 years.

The participants were free to present ideas, judge and evaluate experiences, a process described as "praxis" [31]. The CCM had been implemented one year previously [15] [16]. The first author provided one and a half hours of education about the CCM to selected community and specialist healthcare staff from a community on the west coast of Norway one year prior to this follow-up study.

The participants were asked to reflect over the CCM components related to their own role in encouraging elderly persons to participate in shared decision-making. The main question was "can you please discuss your role in encouraging depressed elderly persons to participate in shared decision-making during the 12 months following the implementation of the CCM and your CCM education". The number of reflections and level of engagement in the discussion of their own responsibility and role on the team were high. According to Liamputtong [31], the success of the focus group method is dependent on the size of the group being suitable for the aim of the study.

The focus group interview was audio-taped and transcribed verbatim. Rolfe [30] [32] [33] argued that empirical evidence of practice gained as a result of reflection may be stronger than that derived from non-naturalistic experimental designs. The sharing of experiences and thoughts about a specific topic can create a deeper understanding through group interaction, leading to a high degree of participation as described by Denzin and Lincoln [34]. The focus group interview was held at the Faculty of Nursing Studies, where the first author is employed.

\subsection{Thematic Analysis}

A thematic analysis was used for the empirical data in order to identify themes [35]. This method is suitable for studies in which at least some of the themes can be identified à priori [36]. Questions of relevance are used as a thematic framework for the analysis [37]. In the present study the researchers used the CCM as a theoretical framework by specifically focusing on decision-making. Additional themes were identified as the analysis progressed and the researchers refined the framework and discussed their individual interpretations of the data. The CCM components were related to each theme to increase the reliability of the coding. This descriptive analysis did not explore issues as deeply as in-depth interviews [38]. In the dialogue, the researcher organises the findings according to the content identified in the data. Excerpts from the data are presented to provide a rich description and support the analysis [39].

The first step involved exploring the interview text to find statements pertaining to the depressed elderly persons' participation in shared decision-making. The text was then structured into a table to identify themes and sub-themes. In this process, the researchers validated the text by discussing how it could be understood and interpreted (Figure 1) as well as how it reflected the different components of the CCM. The emerging theme and sub-themes were important for reaching consensus about the text, as they enabled the researchers to identify and label the meaning embedded in the quotations. 

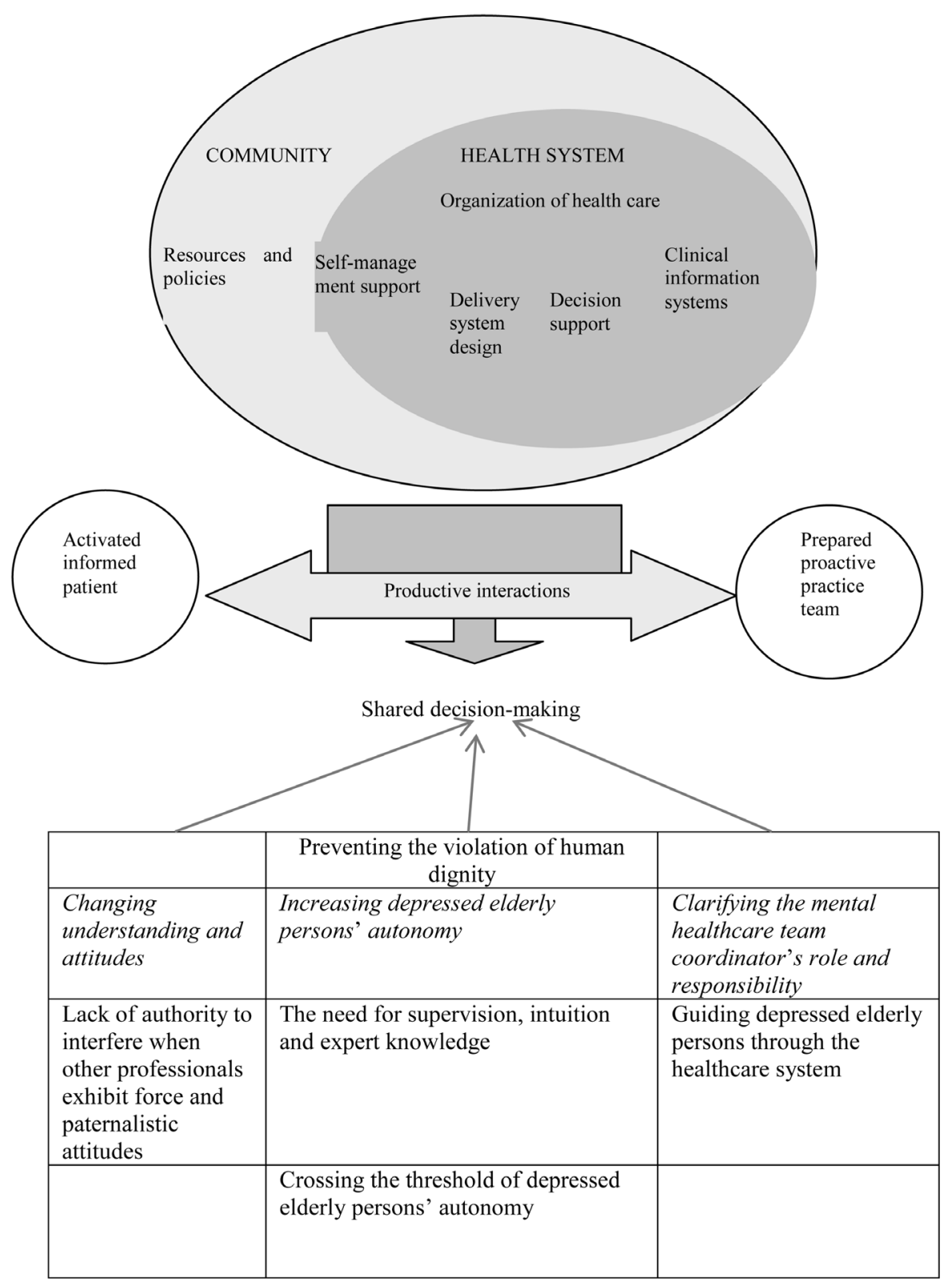

Figure 1. Summary of the study outcomes after implementation of the Chronic Care Model (CCM) [14] [20].

\subsection{Establishing Trustworthiness}

According to Rolfe [30], the truthfulness of the findings can be enhanced through recounting actions and decisions, rather than some idealized version of events. The participatory inquiry process required constant attention to procedures to ensure trustworthiness. The team perceptions can be seen as reflecting self-management in terms of decision-making in the context of depressed older persons. Credibility refers to confidence in the truth of the data and their interpretation [39]. Thus, credibility in this study implied that the perspectives of the participants were represented as clearly as possible and required an understanding of the team's situation. The researchers used quotations from the text in order to help the reader to judge whether or not they succeeded in representing the participants' perspectives. Throughout the research process, the researchers read the transcribed interview text several times, discussing and putting critical questions to it in order to enhance credibility. Three of the researchers have long experience as psychiatric nurses, which may have coloured their understanding of 
the quotations.

\subsection{Ethical Considerations}

The participants were informed about the purpose and method of the study as well as their right to withdraw at any time and that the data would be treated confidentially and their names removed from the transcripts [40]. They gave their permission to audio-tape the interviews. Tee and Lathlean [41] highlighted the need for ongoing consensual decision-making in research and drew attention to adults considered "vulnerable". As the present research involved team members' perceptions of shared decision-making in the context of depressed older persons, the consideration of vulnerability is important. The study was approved by the Regional Ethics Committee of Western Norway (No. 2010/2242) and carried out in accordance with the Ethical Guidelines for Nursing Research in the Nordic countries issued by the Northern Nurses' Federation [42].

\section{Findings}

The overall theme was: Preventing the violation of human dignity based on three themes: Changing understanding and attitudes, Increasing depressed elderly persons' autonomy and Clarifying the mental healthcare team coordinator's role and responsibility. The first theme comprised one sub-theme: Lack of authority to interfere when other professionals exhibit force and paternalistic attitudes. The second theme comprised two sub-themes: The need for supervision, intuition and expert knowledge and Crossing the threshold of depressed elderly persons' autonomy. The third theme had one sub-theme; Guiding depressed elderly persons through the healthcare system.

\subsection{Preventing the Violation of Human Dignity}

A comprehensive understanding emerged through interpretation of the overall theme "Preventing the violation of human dignity" in the light of the CCM components and the development of a proactive practice team. It was considered especially important to build a team approach for depressed elderly persons as shown in Figure 1. Thus the CCM implies shared decision-making and a team approach based on productive interaction that includes an informed and empowered patient, where the latter's role in participation is emphasized. One aspect of the understanding was related to the lack of awareness of power strategies that are often hidden in healthcare relationships. By focusing solely on the depressed elderly person's need to change, the interpretation also demonstrated team members' experiences of lack of reflection on their own role in shared decision-making including failure to acknowledge the risk of forcing depressed elderly persons in a certain direction, the consequence of which can be a violation of human dignity. The depressed elderly persons' participation in shared decisionmaking was mirrored by the following themes; "Changing understanding and attitudes", "Increasing depressed elderly persons' autonomy" and "Clarifying the mental healthcare team coordinator's role and responsibility".

\subsection{Changing Understanding and Attitudes}

Knowledge is necessary in order to change "the attitude" to a team approach and participation in shared decision-making. Team A reported attending a course about how to help depressed elderly persons themselves to prevent the depression becoming more severe. In addition, they worked individually with information on the same theme with focus on participation for the purpose of increasing awareness. They consciously used a cognitive approach in order to change the depressed older persons' way of thinking about their own responsibility and role in shared decision-making. Psycho-educative theory is central in Team A's cognitive approach, which also involved exploring the older persons' experiences from the past. One of the members of Team A stated:

"I think we have managed to change the way we work and have a different focus today than last year". (Team A)

Another participant stated:

"I agree with Team B that this approach has generated a greater understanding of participation". (Team A)

Team A reported receiving feedback from the depressed older persons that their knowledge had increased as a result of greater understanding of productive interactions, which indicates an empowered patient. Some patients 
made comments such as "I finally understand". Team A stated that the increased knowledge of participation gained by the depressed older persons was the main reason for focusing on shared decision-making related to the $\mathrm{CCM}$ and productive interactions:

"It's part of the model that the person must participate in decision-making". (Team A)

Another participant stated:

"It has increased my awareness of the need to change my view of older persons...I really want to strengthen their autonomy and independence". (Team A)

Lack of Authority to Interfere When Other Professionals Exhibit Force and Paternalistic Attitudes

Team A reported having no authority over the behaviour of other healthcare professionals and being unable to tell them what to do. The members of Team A added that they had no opportunity to reflect on how paternalistic attitudes can dominate, which means that older persons were unable to participate. One of the participants stated:

"There is another culture". (Team A)

Team A reported being more aware of the depressed older persons' need to increase their understanding of the meaning of productive interactions and team-building in shared decision-making in order to participate in their own care than is generally the case in the home care service.

\subsection{Increasing Depressed Elderly Persons' Autonomy}

The members of the two teams reflected on cases where they experienced that the depressed older persons were too vulnerable and weak to be empowered to participate in shared decision-making as outlined in the CCM. Team A reported thinking about charity versus autonomy and the ethical dilemmas that arise. Is the person strong enough to take part in decisions regarding her/his own care? In such cases they try to make the person remember her/his own experiences the last time she/he had no strength by posing questions, for example; Do you remember the last time you did not feel strong enough and you needed more home visits but felt better after a few weeks? One participant stated:

"I think that a depressed older person does not want more follow-up and even if you as a professional see a decrease in function in her/his daily life you have to respect her/his decision". (Team A)

Team A reported that in such cases it is of the utmost importance to be aware of the person's history and experiences in order to make her/him more willing to accept help. When not feeling well they do not realise their needs until it is too late. The researcher commented that it seems difficult to find the right balance, with which the members of Team A agreed, adding that nothing they say has any meaning for the depressed older persons. One of the participants stated:

"I've learned a lesson myself here. Sometimes I have to decide for the person. Later I explained why I did the things I did. In this situation I contacted the primary care physician who was the only professional the depressed older person listened to". (Team A)

\subsubsection{The Need for Supervision, Intuition and Expert Knowledge}

The members of Team A commented that they require supervision, intuition and expert knowledge in certain situations. They stated that they need a team as recommended in the CCM including an external supervisor, thus allowing them to discuss and reflect on difficult situations. One of the participants stated:

"My expert knowledge gives me an intuition about the right thing to do in different situations. I know that things pass, that the situation will improve and that most depressed older persons find strategies if they are unable to participate in decision-making". (Team A)

The researcher asked for more information about being guided by intuition:

"I experience my intuition as a barometer that I try hard to adapt to". (Team A) 
The members of Teams A and B reported that in addition to all the suggestions mentioned here, communication is an important part of the CCM and means entering into a dialogue with the depressed elderly person in order to make a holistic decision. The participant from Team B experienced that shared decision-making has a life of its own and goes on regardless:

"You do everything to help the depressed older persons. Shared decisions have to be grounded in knowledge and experience. The need for shared decision-making is more of an intuition and something that emerges in the situation. It's something inside you that tells you the right thing to do". (Team B)

\subsubsection{Crossing the Threshold of Depressed Elderly Persons' Autonomy}

When is the right time to cross the threshold and involve the depressed elderly person in decision-making? The participant from Team B revealed that she has learned to always take the patient seriously, which implies that she sometimes has to make decisions and take responsibility, especially in cases where the patient is unable to do so:

"When the older person is admitted to the psycho-geriatric ward she/he cannot decide anything and refuses to cooperate. We have to help. What form of knowledge is needed in such a situation? This is an example of a knowledge gap and professionals need knowledge in order to encourage participation in shared decision-making”. (Team B)

\subsection{Clarifying the Mental Healthcare Team Coordinator's Role and Responsibility}

The members of team A reported that sometimes the coordinator of the team has to guide the depressed older person through the healthcare system. Two of the members of Team A attended a course on the team coordinator's function in the healthcare sector. They explained that the coordinator should clarify but not map the situation. However, their team did not function in the way described in the CCM. They explained that the coordinator should clarify but not map the situation. This was an important change from their previous view of the coordinator's role. In their opinion, a coordinator should be independent of the institution but only the administrator has such a position. For this reason a coordinator needs contact with the community administration. One of the participants from Team A expected the coordinator to participate in the decision-making process and suggested that this might lead to a discussion of best practice. In such cases the coordinator will need leadership support. In addition, there should be a limit to the number of persons for whom a coordinator can assume responsibility. She stated:

"Until now it has been usual that the coordinator jumps around like a rabbit.

It's a lack of understanding of the authority of the role". (Team A)

Team A reported that the coordinator has to do everything. The various healthcare services do their duty, but the coordinator needs information about the situation. In the team's experience participation and shared decision-making are not followed up and the CCM was far from a reality in their community.

\section{Guiding Depressed Elderly Persons through the Healthcare System}

Team A revealed that their community does not have a coordinator as recommended in the CCM. One of the participants from Team A doubted that a coordinator with overall responsibility could function in practice because she/he is no longer involved with the community home healthcare systems. The coordinator should be independent of any institutional affiliation and able to make her/his own decisions. When the expectations on a coordinator are outlined in this way, the job can seem impossible. She added that the care plan does not have any legal force but merely serves as a guideline when it is necessary to inform a patient about a situation, in other words, help her/him to participate in shared decision-making. Another participant stated:

"In my opinion a coordinator should have an overview, gather the threads, guide the depressed older person and cooperate with her/him to find the right decision". (Team A)

\section{Discussion}

The comprehensive understanding of the findings was the importance of "Preventing the violation of human 
dignity" based on three themes: "Changing understanding and attitudes", "Increasing depressed elderly persons" autonomy" and "Clarifying the mental healthcare team coordinator's role and responsibility". The CCM implies a team approach based on productive interaction as well as an informed and empowered patient, where the latter's role in participation is emphasized. However, greater awareness of the meaning of shared decision-making is necessary in order to prevent the violation of human dignity. This is in accordance with Holm et al. [23], who highlight the fact that lack of participation can cause depressed elderly persons to feel that they are no longer able to master their life. Thus, healthcare team members require more knowledge about how depressed older patients need to participate and its implications for shared decision-making as well as increased awareness of paternalistic attitudes and power strategies. A problem arises if shared decision-making does not reduce depressed elderly persons' own perceptions of being violated. Self-determination has been outlined as the most significant human right and can be seen as an existential dimension of being in the world related to dignity [43]. In the CCM, Wagner et al. [14] [20] shifted the focus from didactic patient education to encouragement and support for shared decision-making. The care of depressed elderly persons should emphasize empowerment and participation, which can be a means of preventing the violation of human dignity. However, it must also be acknowledged that although persons are involved in their own care, they may sometimes feel unable to participate. Research has revealed that persons who are actively involved in shared decision-making are less likely to withdraw from the caregiver-patient relationship [9] [44].

The findings revealed that healthcare team members need to change understanding and attitudes with focus on the elderly person's change process. This can mean setting priorities for making changes in line with the CCM, which is supported by Montori et al. [45], who revealed that there is a need to revisit decisions and monitor barriers that influence implementation. Ofstad [46] described high-integrated decisions as deeply rooted in the decision-maker's ethical value system, as well as based on logic and deep-seated personal traits. The team's ethical value system is thus involved in every part of productive interactions and forms part of the decision-making process. Deepening the opportunity to reflect with colleagues can change one's understanding and attitudes. Another aspect that emerged in the focus group is that supervision can change some of the paternalistic attitudes among healthcare professionals. Depressed elderly persons were often described in a traditional way, i.e. as passive rather than active recipients of care, and healthcare professionals failed to empower them to take responsibility for their own life situation [47]. A new meaning of caring for depressed elderly persons is required because they often resent paternalistic attitudes exhibited by healthcare professionals.

The depressed elderly persons were not always able to participate in the dialogue, which makes it important to increase their autonomy. The decision to take over was a balancing act that can be related to each human being's need for autonomy. As an ethical principle, autonomy includes liberty, which implies independence from controlling influences and the capacity for intentional action [48]. Lack of knowledge pertaining to the right time to cross the threshold of the depressed older persons' autonomy needs to be addressed. Improvements imply reflecting on previous actions and using the lessons learned so that failure becomes a learning experience. Acting in a morally independent way based on ethically justified standpoints can prevent the use of power strategies such as corruption, deception, opportunism and shallowness as well as increasing awareness of respect and sensitivity to the depressed older person's perception of threats to her/his dignity and integrity.

Clarifying the mental healthcare team coordinator's role and responsibility revealed that teams without visible leadership reported a lack of resources and inability to obtain support from the administration [14] [20]. Therefore, one important prerequisite for team success is clarification of the team coordinator's role and responsibility [22]. The coordinator is responsible for providing a choice and explaining available options, both of which are important aspects of the shared decision-making process [49].

Health care providers as represented by team members in this study need greater awareness of the meaning of shared decision-making. The team members do not seem to be capable of their own attitudes that can influence the depressed old person's autonomy in the participation of shared decision making. This is a form of one's intuition ability. Being in tune with the other that can be a part advocacy, as well as a significant factor in quality of care [50]. Such care can be a difficult power balance when team members should decide what is right and wrong because it can violate human dignity [51]. Issues of autonomy occur in a supervisory situation [52] where the supervisor is responsible for conducting the supervision [53]. The supervisor has to be autonomous and have courage as well as the authority to make decisions [54]. The ability to assume responsibility is reflected in supervision, which increased the team's knowledge and skills. Thus supervision can enhance the ability to be just in shared decision-making [55]. Reflections how to include the depressed old person in the supervision, the team 
need to be utmost aware of how to obtain real participation of the depressed older persons due to the legal right to have a say in their own care plan. The team coordinator needs to use their own judgment to obtain and make use of knowledge and information [56]. The coordinator role is guiding depressed elderly persons through the healthcare system which involves acting as someone who the depressed elderly person can trust [57]. The CCM described the coordinator as a case manager who has an essential role in ensuring shared decision-making for chronically ill patients. The coordinator should be a nurse or physician and responsible for creating a dialogue with the patient where the coordinator must be aware of hidden power aspects, to less violation of depressed elderly persons' dignity. The coordinator should increase understanding of the fact that although depressed elderly persons often feel powerless, they are also moral agents with their own values [58].

\section{Recommendations}

Recommendations for healthcare professionals are by working in teams healthcare professionals can better inform depressed older persons about the meaning of shared decision-making. Many depressed older persons are unfamiliar with the notion of being invited to share in decision making, thus it may be helpful to explain to them that they have certain choices that are important to discuss before arriving at a joint decision [59], which may reduce uncertainty. It is important to encourage discussion, among other things to correct any misconceptions. Shared decision-making can provide a framework for communicating about choices, thus guiding the decision-making process, but it requires the healthcare professional to assume responsibility.

\section{Study Limitations}

A limitation of the study is the small number of participants ( 3 members of one community mental health team and one geriatric nurse from a psycho-geriatric ward), which makes it difficult to generalize the results to community settings in other parts of Norway or to other countries and communities. Kitzinger [60] suggested that the ideal focus group size is between four and eight participants. A group with more than eight people can be difficult to manage and some participants might find it impossible to make themselves heard in a big group where everyone else is trying to talk [61]. Smaller groups provide an environment where the participants can engage in active discussions [30]. According to Morgan et al. [62], in some cases a larger group made it difficult for moderators to encourage interactive discussion. Instead of highlighting the number of members who should be included in a focus group, we concentrated on the group dynamic [31]. We were aware that the number of participants is important, but according to Hopkins [63], aspects such as age and professional affiliation, the location of the focus group meeting and the sensitivity of the topic under discussion are equally relevant.

A further limitation may be that the authors influenced each other by repeatedly discussing the text before agreeing on the main theme, themes and sub-themes. More research is necessary on the problems inherent in participation of depressed elderly persons and its implications for shared decision-making.

\section{Conclusions}

This study reveals that in order to prevent the violation of human dignity, team members must be aware of power strategies that are often hidden in the relationships. The team members do not seem to be aware of such strategies when trying to convince themselves that the depressed elderly person is willing to participate. Greater knowledge is necessary in order to change attitudes to and understanding the role of team members in the participation of depressed elderly persons in shared decision-making.

This study reveals the need for further research on depressed elderly persons' participation in shared decisionmaking based on the CCM. However, such participation seems to constitute a barrier, especially in relation to some of the principles of collaboration contained in the CCM.

\section{Conflict of Interests}

The authors of this paper declare no conflict of interests.

\section{Acknowledgements}

We would like to express our deep thanks to the team members who participated. We also want to thank Gullvi Nilsson and Monique Federsel for reviewing the English language. 


\section{Sources of Funding}

The study has been supported by grants from the Research Council of Norway, Chronic Disease Management implementation and coordination of health care systems for depressed elderly persons (NFR, No. 204238/V50).

\section{References}

[1] World Health Organization (2001) Mental Health: New Understanding, New Hope. World Health Report, Geneva.

[2] Charles, C., Gafni, A. and Whelan, T. (1997) Shared Decision Making in the Medical Encounter: What Does It Mean? (Or, It Takes at Least Two to Tango). Social Science \& Medicine, 44, 681-692. http://dx.doi.org/10.1016/S0277-9536(96)00221-3

[3] Whitney, S.N., McGuire, A.L. and McCullough, L.B. (2003) A Typology of Shared Decision Making, Informed Consent, and Simple Consent. Annual of Internal Medicine, 140, 54-59. http://dx.doi.org/10.7326/0003-4819-140-1-200401060-00012

[4] Flottorp, S.A., Jamtvedt, G., Gibis, B. and McKee, M. (2008) Using Audit and Feedback to Health Professionals to Improve the Quality and Safety of Health Care. http://www.euro.who.int/_ data/assets/pdf_file/0003/124419/e94296.pdf

[5] Davidson, L. (2005) Recovery, Self-Management and the Expert Patient Perspective. Journal of Mental Health, 1, 2535. http://dx.doi.org/10.1080/09638230500047968

[6] Cribb, A. and Entwistle, V.A. (2011) Shared Decision Making: Trade-Offs between Narrower and Broader Conceptions. Health Expectation, 14, 210-219. http://dx.doi.org/10.1111/j.1369-7625.2011.00694.x

[7] Drake, R.E. and Deegan, P.E. (2009) Shared Decision Making Is an Ethical Imperative. Psychiatric Services, $60,1007$.

[8] Koch, T., Jenkin, P. and Kralik, D. (2004) Chronic Illness Self-Management: Locating the "Self". Journal of Advanced Nursing, 48, 484-492. http://dx.doi.org/10.1111/j.1365-2648.2004.03237.x

[9] Loh, A., Simon, D., Wills, Kriston, I., Niebling, W. and Härter, M. (2007) The Effects of a Shared Decision-Making Intervention in Primary Care of Depression: A Cluster-Randomized Controlled Trial. Patient Education and Counselling, 67, 324-332. http://dx.doi.org/10.1016/j.pec.2007.03.023

[10] Patel, S.R. and Bakken, S. (2010) Preferences for Participation in Decision-Making among Ethnically Diverse Patients with Anxiety and Depression. Community Mental Health Journal, 46, 466-473. http://dx.doi.org/10.1007/s10597-010-9323-3

[11] International Council of Nurses (ICN) (2000) Code of Ethics for Nurses. ICN, Geneva.

[12] Tee, S., Lathlean, J., Herbert, L., Coldham, T., East, B. and Johnson, T.J. (2007) User Participation in Mental Health Nurse Decision-Making: A Co-Operative Enquiry. Journal of Advanced Nursing, 60, 135-145. http://dx.doi.org/10.1111/j.1365-2648.2007.04345.x

[13] Marshall, S.S., Haywood, K.L. and Fitzpatrick, R. (2005) Patient Involvement and Collaboration in Shared Decision Making: A Structured Review to Inform Chronic Disease Management. Report from the Patient-Reported Health Instruments Group to the Department of Health. http://phi.uhce.ox.ac.uk/pdf/phig patient involvement report.pdf

[14] Wagner, E.H., Glasgow, R.E., Davis, C., Bonomi, A.E., Provost, L., McCulloch, D., Carver, P. and Sixta, C. (2001) Quality Improvement in Chronic Illness Care: A Collaborative Approach. Joint Commission Journal on Quality Improvement, 27, 63-80.

[15] Holm, A.L. and Severinsson, E. (2013) Surviving Depressive Ill-Health: A Systematic Qualitative Review of Older Persons' Narratives. Nursing \& Health Sciences, 16, 131-140. http://dx.doi.org/10.1111/nhs.12071

[16] Holm, A.L. and Severinsson, E. (2013) Interdisciplinary Team Collaboration during Discharge of Depressed Older Persons-A Norwegian Qualitative Implementation Study. Nursing Research and Practice, 2013, Article ID: 794743. http://dx.doi.org/10.1155/2013/794743

[17] Holm, A.L. and Severinsson, E. (2013) Reflections on the Ethical Dilemmas Involved in Promoting Self-Management. Nursing Ethics, 21, 402-413. http://dx.doi.org/10.1177/0969733013500806

[18] Lyberg, A., Holm, A.L., Lassenius, E., Berggren, I. and Severinsson, E. (2013) Older Persons’ Experiences of Depressive Ill-Health and Family Support. Nursing Research and Practice, 2013, Article ID: 837529. http://dx.doi.org/10.1155/2013/837529

[19] Unützer, J., Rubenstein, L., Katon, W.J., Tang, L.Q., Duan, N.H., Lagomasino, I.T. and Wells, K.B. (2001) Two-Year Effects of Quality Improvement Programs on Medication Management for Depression. JAMA Psychiatry, 58, 935-942. http://dx.doi.org/10.1001/archpsyc.58.10.935

[20] Wagner, E.H., Austin, B.T., Davis, C., Hindrash, M., Schaefer, J. and Bonomi, A. (2001) Improving Chronic Illness 
Care: Translating Evidence into Action. Health Affairs, 20, 64-78. http://dx.doi.org/10.1377/hlthaff.20.6.64

[21] Coulter, A., Parsons, S. and Askham, J. (2008) Where Are the Patients in Decision-Making about Their Own Care? World Health Organization, World Health Organization 2008 and World Health Organizaiton, on Behalf of the European Observatory Health Systems and Policies 2008.

http://www.who.int/management/general/decisionmaking/WhereArePatientsinDecisionMaking.pdf

[22] Holm, A.L. and Severinsson, E. (2012) Chronic Care Model for the Management of Depression: Synthesis of Barriers to, and Facilitators of Success. International Journal of Mental Health Nursing, 21, 513-523. http://dx.doi.org/10.1111/j.1447-0349.2012.00827.x

[23] Holm, A.L., Lyberg, A., Lassenius, E., Berggren, I. and Severinsson, E. (2013) Older Persons' Lived Experiences of Depression and Self-Management. Issues in Mental Health Nursing, 34, 757-764. http://dx.doi.org/10.3109/01612840.2013.809829

[24] Park, E.J. (2012) An Integrated Ethical Decision-Making Model for Nurses. Nursing Ethics, 19, 139-159. http://dx.doi.org/10.1177/0969733011413491

[25] Simon, J.S., Aguar, L., Kunz, N.R. and Lei, D. (2004) Extended-Release Venlafaxine in Relapse Prevention for Patients with Major Depressive Disorder. Journal of Psychiatric Research, 38, 249-257. http://dx.doi.org/10.1016/j.jpsychires.2003.10.004

[26] Stacey, D., Menard, P., Gaboury, I., Jacobsen, M., Sharif, F., Ritchie, L. and Bunn, H. (2008) Decision-Making Needs of Patients with Depression: A Descriptive Study. Journal of Psychiatric and Mental Health Nursing, 15, $287-295$. http://dx.doi.org/10.1111/j.1365-2850.2007.01224.x

[27] Van de Bovenkamp, H. and Trappenburg, M. (2009) Reconsidering Patient Participation in Guideline Development. Health Care Analysis, 17, 198-216. http://dx.doi.org/10.1007/s10728-008-0099-3

[28] Church, J., Saunders, D., Wanke, M., Pong, R., Spooner, C. and Dorgan, M. (2002) Citizen Participation in Health Decision-Making: Past Experience and Future Prospects. Journal of Public Health Policy, 23, 12-32. http://dx.doi.org/10.2307/3343116

[29] Polit, D.F. and Beck, C.T. (2012) Nursing Research: Generating and Assessing Evidence for Nursing Practice. Wolters Kluwer Health, Philadelphia.

[30] Rolfe, G. (2005) Validity, Trustworthiness and Rigour: Quality and the Idea of Qualitative Research. Journal of Advanced Nursing, 53, 304-310. http://dx.doi.org/10.1111/j.1365-2648.2006.03727.x

[31] Liamputtong, P. (2011) Focus Group Methodology Principles and Practice. Sage, London.

[32] Rolfe, G. (2005) The Deconstructing Angel: Nursing, Reflection and Evidence-Based Practice. Nursing Inquiry, 12, 78-86. http://dx.doi.org/10.1111/j.1440-1800.2005.00257.x

[33] Rolfe, G. (2006) Judgements without Rules: Towards a Postmodern Ironist Concept of Research Validity. Nursing Inquiry, 13, 7-15. http://dx.doi.org/10.1111/j.1440-1800.2006.00298.x

[34] Denzin, N.K. and Lincoln, Y.S. (1994) Handbook of Qualitative Research. Sage Publications, London.

[35] Bryman, A. and Burgess, R.G. (1994) Analyzing Qualitative Data. Routledge, London. http://dx.doi.org/10.4324/9780203413081

[36] Rithcie, J. and Lewis, J. (2003) Qualitative Research Practice: A Guide for Social Science Students and Researchers. Sage, London.

[37] Pope, C., Ziebland, S. and Mays, N. (2000) Qualitative Research in Health Care. Analysing Qualitative Data. British Medical Journal, 320, 114-116. http://dx.doi.org/10.1136/bmj.320.7227.114

[38] Sandelowski, M. (2001) Focus on Research Methods. Whatever Happened to Qualitative Description? Research in Nursing \& Health, 23, 334-340. http://dx.doi.org/10.1002/1098-240X(200008)23:4<334::AID-NUR9>3.0.CO;2-G

[39] Polit, D.F. and Beck, C.T. (2010) Essentials of Nursing Research: Appraising Evidence for Nursing Practice. Wolters Kluwer/Lippincott Williams \& Wilkins, Philadelphia.

[40] World Medical Association (2008) Declaration of Helsinki. Ethical Principles for Medical Research Involving Human Subjects, 2008. http://www.wma.net/en/20activities/10ethics/10helsinki/

[41] Tee, S.R. and Lathlean, J.A. (2004) The Ethics of Conducting a Cooperative Inquiry with Vulnerable People. Journal of Advanced Nursing, 47, 536-543. http://dx.doi.org/10.1111/j.1365-2648.2004.03130.x

[42] Northern Nurses' Federation (NNF) (2003) Ethical Guidelines for Nursing Research in the Nordic Countries. http://www.sykepleien.no/ikbViewer/content/337889/SSNs\%20etiske\%20retningslinjer.pdf

[43] Barker, P. (2011) Mental Health Ethics: The Human Context. Routledge, Abingdon.

[44] Clever, S.I., Ford, D.E., Rubenstein, L.V., Rost, K.M., Meredith, L.S., Sherbourne, C.D., et al. (2006) Primary Care Patients' Involvement in Decision-Making Is Associated with Improvement in Depression. Medical Care, 44, 398-405. 
http://dx.doi.org/10.1097/01.mlr.0000208117.15531.da

[45] Montori, V.M., Gafni, A. and Charled, C. (2006) A Shared Treatment Decision-Making Approach between Patients with Chronic Conditions and Their Clinicians: The Case of Diabetes. Health Expectations, 9, 25-36. http://dx.doi.org/10.1111/j.1369-7625.2006.00359.x

[46] Ofstad, H. (1961) An Inquiry into the Freedom of Decision. Norwegian Universities Press, Oslo.

[47] Henriksen, E. and Rosenqvist, U. (2003) Contradictions in Elderly Care: A Descriptive Study of Politicians' and Managers' Understanding of Elderly Care. Health \& Social Care in the Community, 11, 27-35. http://dx.doi.org/10.1046/j.1365-2524.2003.00403.x

[48] Beauchamp, T.L. and Childress, J. (2013) Principles of Biomedical Ethics. 7th Edition, Oxford University Press, Oxford.

[49] Birmingham, J. (2009) Patient Choice in the Discharge Planning Process. Professional Case Management, 14, $296-309$. http://dx.doi.org/10.1097/NCM.0b013e3181c3d3c5

[50] Spence, K. (2011) Ethical Advocacy Based on Caring: A Model for Neonatal and Paediatric Nurses. Journal of Paediatrics and Child Health, 47, 642-645. http://dx.doi.org/10.1111/j.1440-1754.2011.02178.x

[51] Martinsen, K. and Eriksson, K. (2009) To See and to Realize, through Various Forms of Evidence. Akribe, Oslo. (In Swedish and Norwegian)

[52] Magnusson, A., Severinsson, E. and Lützèn, K. (2003) Reconstructing Mental Health Nursing in Home Care. Journal of Advanced Nursing, 43, 351-359. http://dx.doi.org/10.1046/j.1365-2648.2003.02723.x

[53] Berggren, I. and Severinsson, E. (2003) Nurse Supervisors' Actions in Relation to Their Decision-Making Style and Ethical Approach to Clinical Supervision. Journal of Advanced Nursing, 41, 615-622. http://dx.doi.org/10.1046/j.1365-2648.2003.02573.x

[54] Bégat, I.B. and Severinsson, E. (2001) Nurses' Reflections on Episodes Occurring during Their Provision of Care-An Interview Study. International Journal of Nursing Studies, 38, 71-77. http://dx.doi.org/10.1016/S0020-7489(00)00060-2

[55] Berggren, I. (2005) Ethics in Clinical Nursing Supervision. An Analysis of Fundamental Ethical Issues of Clinical Nursing Supervision, with Special Reference to Ethical Decision Making. University of Oslo, Oslo. (Dissertation)

[56] Cornelissen, E., Mitton, C. and Sheps, S. (2011) Knowledge Translation in the Discourse of Professional Practice. International Journal of Evidence Based Healthcare, 9, 184-188. http://dx.doi.org/10.1111/j.1744-1609.2011.00215.x

[57] Erikson, K. (2006) The Suffering Human Being. Nordic Studies Press, Chicago.

[58] Redman, B.K. (2005) The Ethics of Self-Management Preparation for Chronic Illness. Nursing Ethics, 12, 361-369. http://dx.doi.org/10.1191/0969733005ne8010a

[59] Hoffman, T.C., Légaré, F., McNamara, K., McCaffery, K., Trevena, L.J., Hudson, B., Glasziou, P.P. and Del Mar, C.B. (2014) Shared Decision Making: What Do Clinicians Need to Know and Why Should They Bother? Medical Journal of Australia, 201, 35-39. http://dx.doi.org/10.5694/mja14.00002

[60] Kitzinger, J. (2005) Focus Group Research: Using Group Dynamics to Explore Perceptions, Experiences and Understandings. In: Holloway, I., Ed., Qualitative Research in Health Care, Open University Press, Berkshire, 56-70.

[61] Smithson, J. (2008) Focus Groups. In: Alasuutari, P., Bickman, L. and Brannen, J., Eds., Handbook of Social Research Methods, Sage, Thousand Oaks, 357-430.

[62] Morgan, D.L. (2002) Focus Group Interviewing. In: Gubrium, J.F. and Holstein, J.A., Eds., Handbook of Interviewing Research: Context \& Method, Sage, Thousand Oaks, 141-159.

[63] Hopkins, P.E. (2007) Thinking Critically and Creatively about Focus Groups. Area, 39, 528-535.

http://dx.doi.org/10.1111/j.1475-4762.2007.00766.x 
Scientific Research Publishing (SCIRP) is one of the largest Open Access journal publishers. It is currently publishing more than 200 open access, online, peer-reviewed journals covering a wide range of academic disciplines. SCIRP serves the worldwide academic communities and contributes to the progress and application of science with its publication.

Other selected journals from SCIRP are listed as below. Submit your manuscript to us via either submit@scirp.org or Online Submission Portal.
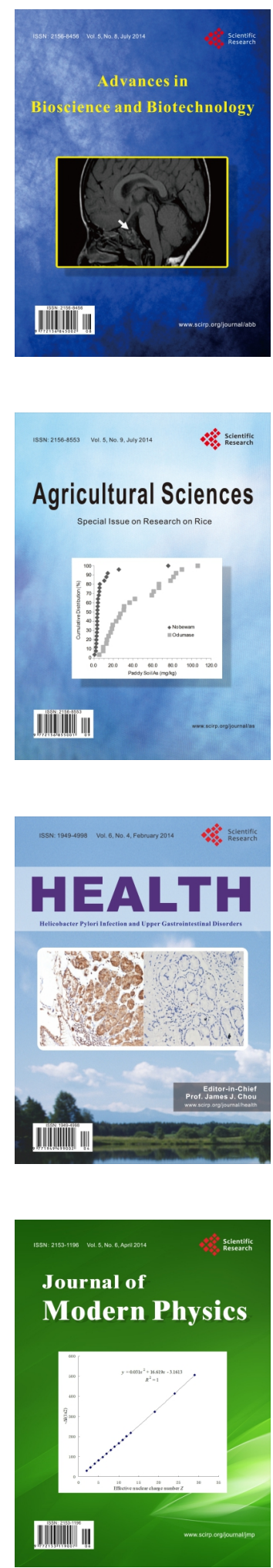
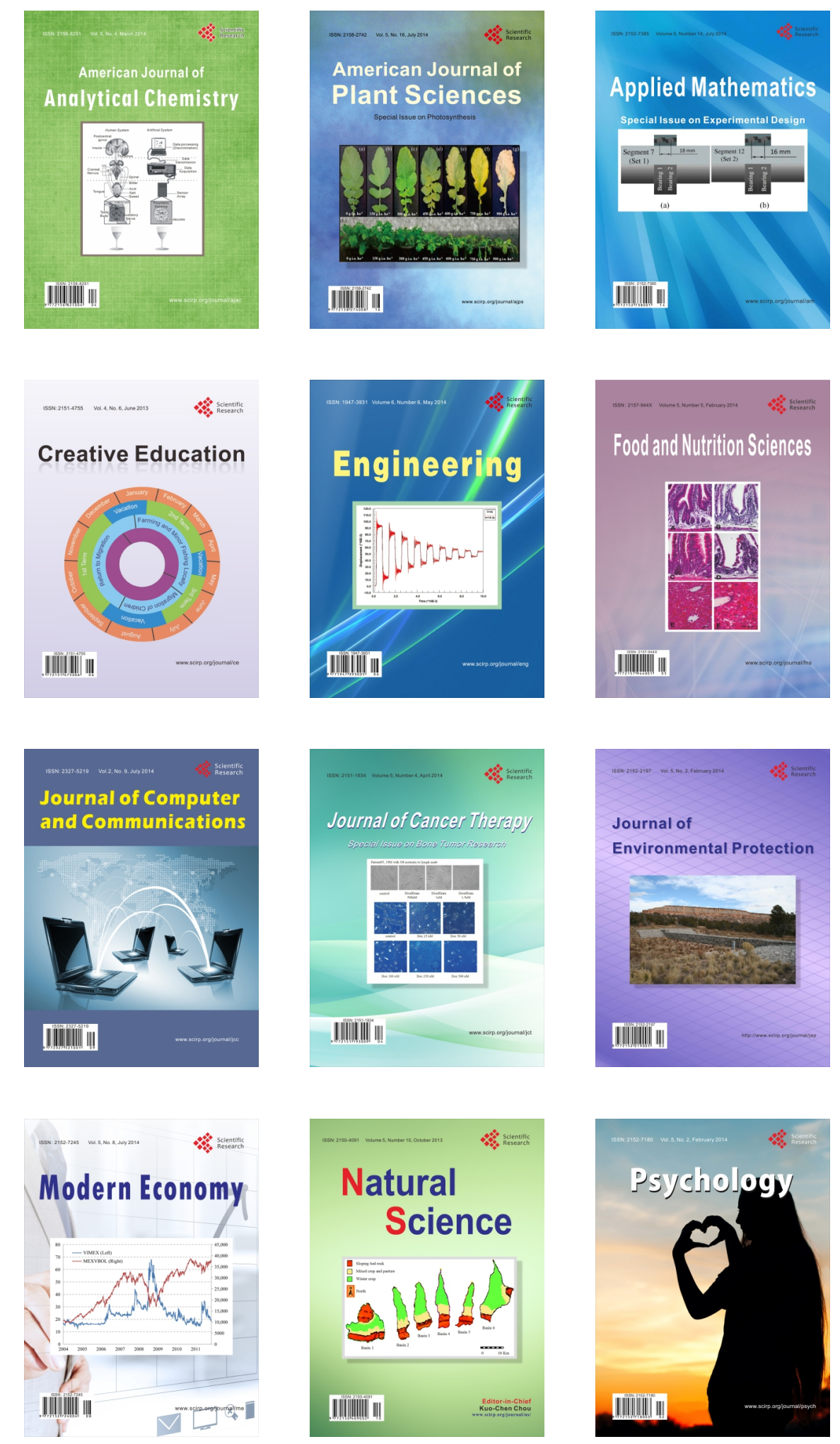